\title{
LARYNGEAL GRANULAR CELL TUMOR; RARE LOCATION
}

\author{
Sedat Aydın", Arif Şanlı ${ }^{1}, \ddot{O}_{z}$ lem Çelebi ${ }^{1}$, Emin Ayduran $^{1}$, Gecer Melin ${ }^{2}$
}

Dr. Lütfi Kirdar Kartal Education and Research Hospital, Istanbul, Turkey: Department of Otolaryngology ${ }^{1}$, Department of Pathology ${ }^{2}$

Summary: Granular cell tumors are benign subcutaneous or submucosal lesions of neurogenic origin. In this case study one patient was diagnosed and treated successfully with complete surgical resection of a laryngeal granular cell tumor that was originated from the left arytenoid region that very rare location. There is no evidence of recurrence 2 years after surgery. Granular cell tumors should be considered in the differential diagnosis of laryngeal masses, particularly in the posterior glottis.

Key words: Granular cell tumor, Abrikossoff's tumor; Laryngeal neoplasm; Hoarseness

\section{Introduction}

Granular cell tumors (GCTs) are relatively uncommon benign laryngeal lesions thought to originate from schwann cells. They were first described by Abrikossoff in 1926 and also known as Abrikossof's tumor (1). The larynx is an uncommon location for these tumors, accounting for approximately $3 \%$ of adult cases. They located most commonly on the posterior two thirds of the vocal fold and arytenoid's region. The gross appearance of them is that of a well-circumscribed, firm, pink or greyish yellow mass. The mass is solitary, polypoid, sessile, papillary, or cystic. It grows slowly, with patients presenting an average of 7 months after initiation of symptoms. Although some patients may be asymptomatic, common symptoms are hoarseness, cough, dysphagia, odynophagia, otalgia, stridor, and hemoptysis. Most often, the diagnosis is a surprise to the surgeon, made after histological examination of biopsied material from direct laryngoscopy $(7,8,11)$. We presented a patient with laryngeal GCT originated from the left arytenoid region which was very rare location, under review of the literature.

\section{Case report}

A 38-year-old male patient was admitted to our clinic complaining of worsening hoarseness, non-productive cough and foreign body sensation in the throat. His complaints started six months before admission and he stated that they had noticeably worsened over the two months. The patient was not a drinker and had no pertinent medical history except for cigarette smoking status that was twenty cigarettes per day over ten years. He hadn't any history of endolaryngeal intubation as well. A laryngeal rigid endo- scopic examination revealed a mass $(3 \times 7 \mathrm{~mm})$ with smooth surface was originated from the medial side of the left arytenoid (Fig. 1). The lesion obscured the posterior two thirds of the left vocal cord, preventing complete glottic closure during phonation. Then he was assessed for laryngostroboscopic examination in our voice laboratory. Although there was a vocal cord vibration, motion of the vocal cords is asymetric and aperiodic. His voice intensity reduced and his maximum phonation time (MPT) was shortened (MPT $=17$ secs, Fundamental frequency $(\mathrm{Fo})=150 \mathrm{~Hz})$ There was no cervical lymphadenopathy, and the rest of the head and neck examination was normal. Informed consent was obtained before the surgery. Since the base of the lesion was not wide and because its surface was covered with proper

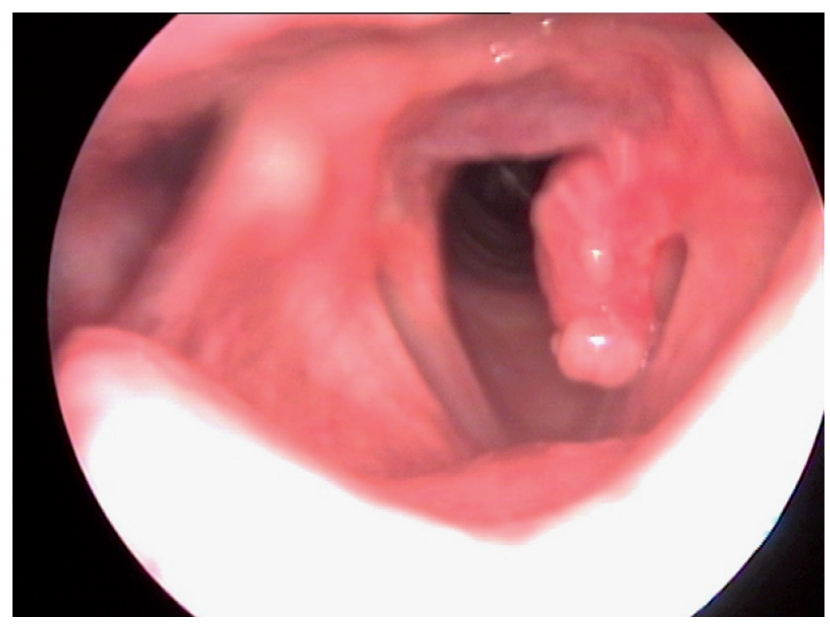

Fig. 1: Endoscopic appearance of Abrikossoff tumor that was originated from the medial side of the left arytenoid. 


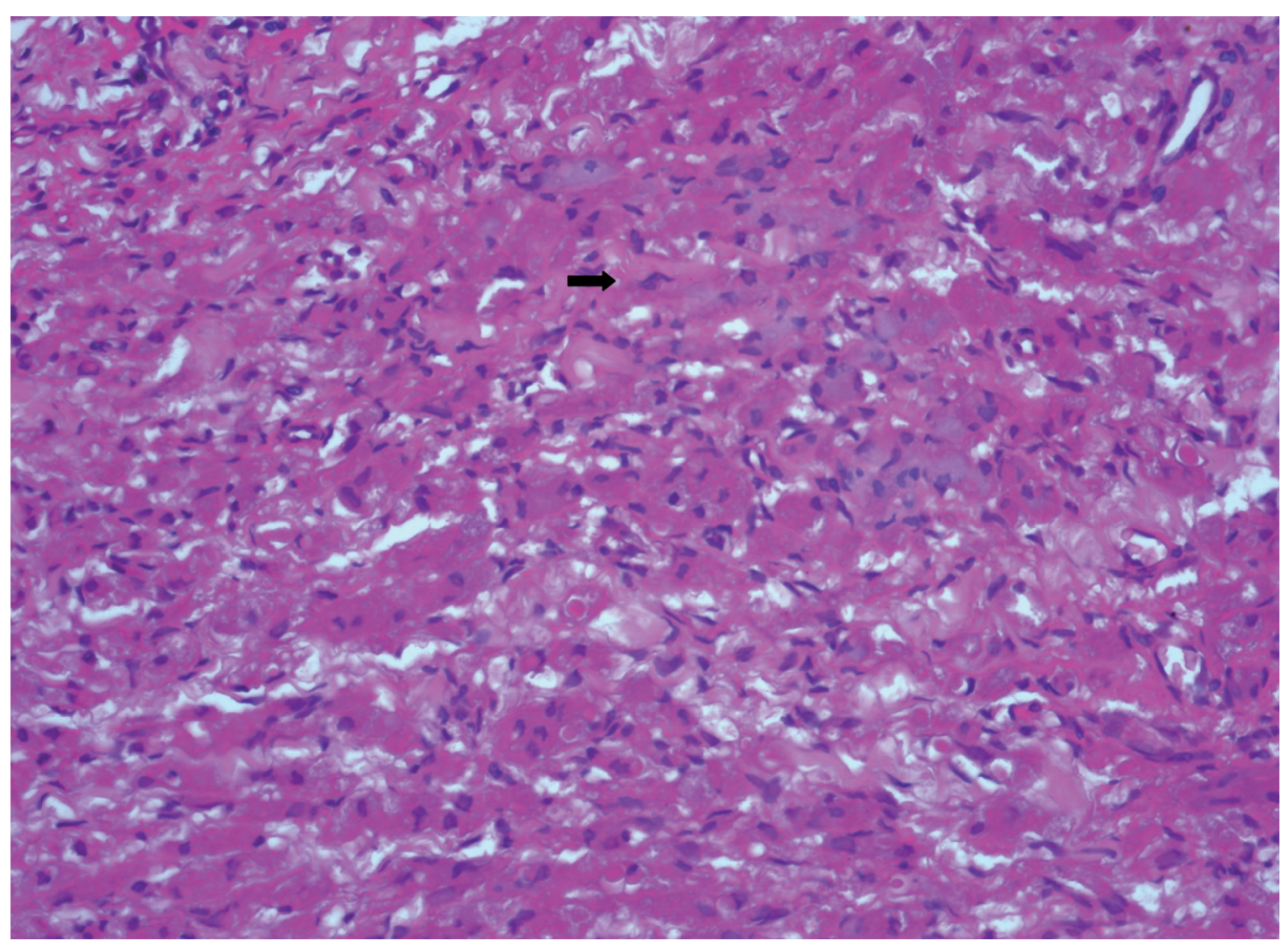

Fig. 2a: Low-power histologic appearance of the tumor: large, polygonal cells arranged in sheets with an abundant granular cytoplasm (black arrow). (H\&E, original magnification x 200).

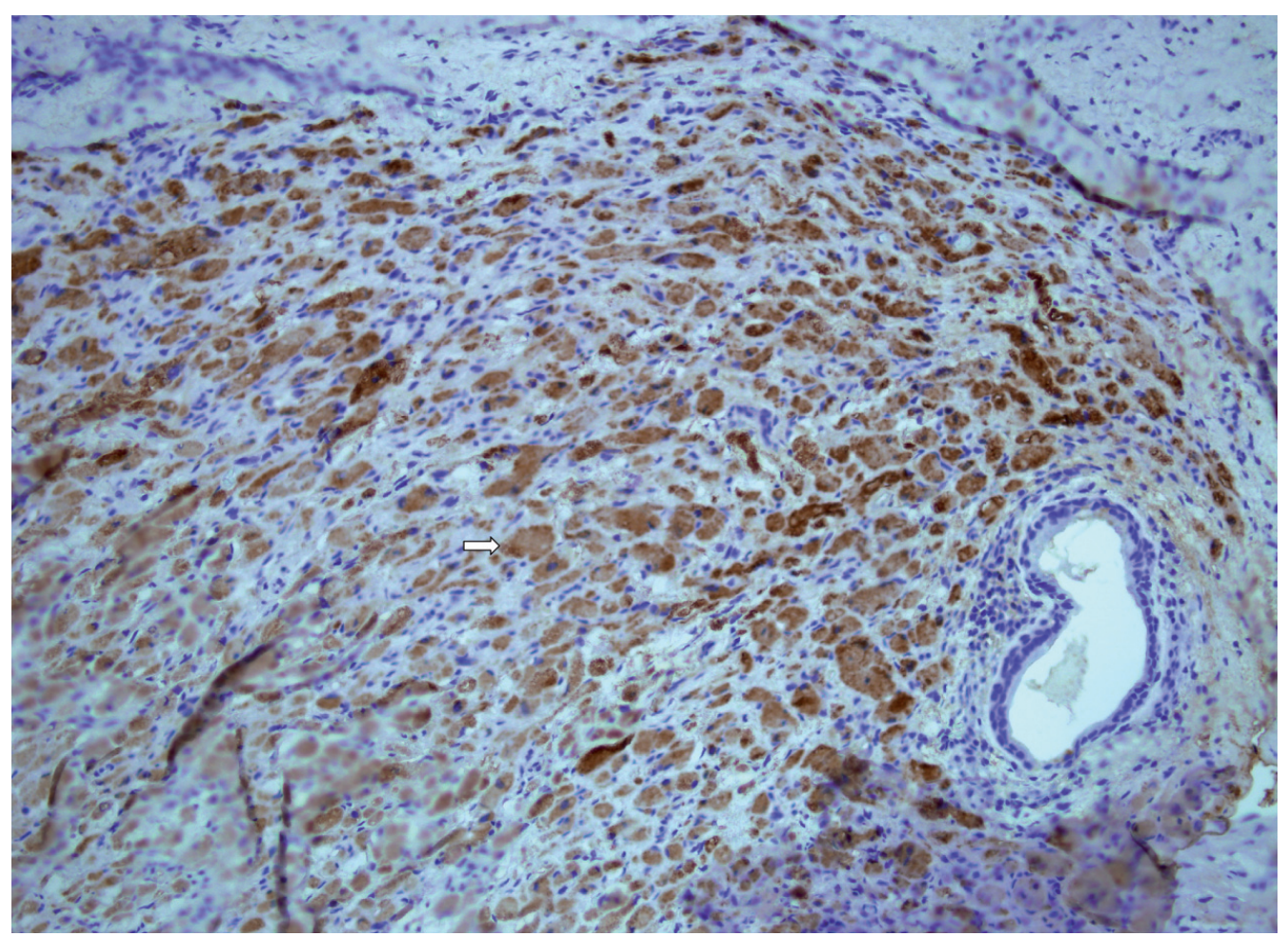

Fig. 2b: Hematoxylin and eosin staining combined with immunohistochemical staining with a monoclonal antibody to S-100 protein shows that the cytoplasm is positive. (white arrow) (H\&E, original magnification $\mathrm{x} 200)$. 
mucosa, a laryngeal MR was not needed. Suspension microlaryngoscopy was planned for pathologic diagnosis and microscopic tumor resection. The tumor was excised completely with cold instruments. The patient had an uneventful postoperative course and regained normal voice. Although the lesion resembled a granuloma, a histopathologic examination revealed a GCT. These polygonal granular cells stained positive with S-100 (Fig. 2a,b). Two years after surgery, he is pleased with his voice outcome and has no evidence of tumor recurrence.

\section{Discussion}

GCTs are benign and rare lesions. They can arise in any organ in the body, but they have been mostly seen on the upper aerodigestive tract. The anterior part of the tongue and the larynx are the first and second most common sites of these tumors, respectively. Symptoms depend on the localization and size of the tumor. The most common symptoms for laryngeal GCTs are hoarseness, cough, hemoptysis, stridor, otalgia, and dysphagia $(5,7)$. The symptoms in our cases were weakening hoarseness, non-productive cough and foreign body sensation in the throat. There are publications in the literature about GCT that are located in the larynx $(2,7,9,11)$. If this tumor is found in children, a differential diagnosis with juvenile laryngeal papilloma should be made $(3,10)$. Since the lesion was located posteriorly, it was a surprise for us to see the tissue that we excised as a granuloma came out to be a granular cell tumor after histopathological exam.

Fifty to $65 \%$ of laryngeal GCTs have pseudoepitheliomatous hyperplasia, which can lead to misinterpretation owing to the similarity of these lesions to squamous cell carcinoma (5). Because of this property of the tumor, it is important to cooperate with the pathologist regularly and to inform the pathologist about the clinic, location and surface properties of the tumor. Otherwise, this situation may lead the surgeon to treat the patient inappropriately and irreversibly.

Once the diagnosis of a benign GCT is confirmed. The treatment of choice is complete excision using a cold knife or laser, with free margins to minimize the risk of residual disease and minimal functional disturbances. Large lesions may require laryngofissure and partial laryngectomy. When the surgical excision is performed properly, the curative rate is about $92 \%$ with a recurrence rate of $2-8 \%$. Radiation therapy is a poor treatment option as these tumors are radio resistant $(2,3)$. Although these tumors are located mostly on the posterior thirds of the vocal cords and on the posterior glottis, a few of them can be on the subglottical area, postcricoidal area and on the arytenoids $(3,8)$. In an English literature, laryngeal GCT originated from the arytenoid that is on a very rare localization was reported only by Jeremy et al (11). Because of this, we thought it is appropriate to present our case with laryngeal GCT originated from the arytenoid.

We should hope that this very rare tumor, in addition to the fact that it does not have any profound symptomatology $(5,10,11)$, will be a pathological diagnosis that we come across by coincidence, keeping in mind that it may be among the posteriorly located glottis pathologies. Moreover, a tight cooperation should be made with the pathology expert so that a neat histopathological exam can be made.

\section{References}

1. Abrikossoff A. Uber myome ausgehend von der quer gesteiften willkurlichen muskulatur.Virchows Arch Pathol Anat Histopathol 1926;260:215-33.

2. Arevalo C, Maly B, Eliashar R, Gross M. Laryngeal granular cell tumor. J Voice. 2008;22:339-42.

3. Conley SF, Milbrath MM, Beste DJ. Pediatric laryngeal granular cell tumor. J Otolaryngol. 1992;21:450-3.

4. Enoz M, Kiyak E, Katircioglu S, Gulluoglu M. Abrikossoff tumor of the larynx. Acta Medica (Hradec Kralove). 2007;50:157-8.

5. Fanburg-Smith JC, Meis-Kindblom JM, Fante R, Kindblom LG. Malignant granular cell tumor of soft tissue: diagnostic criteria and clinicopathologic correlation. Am J Surg Pathol. 1998;22:779-94.

6. Kawaida M, Fukuda H, Kohno N. Granular cell tumors arising nearly simultaneously in the larynx and subcutaneous cervical region. Ear Nose Throat J. 2000;79:162-6.

7. Pelucchi S, Amoroso C, Grandi E, Carinci F, Pastore A. Granular cell tumour of the larynx: literature review and case report. J Otolaryngol. 2002;31:234-5.

8. Rebeiz EE, Shapshay SM. Benign lesions of the larynx. In: Byron J. Bailey, Pillsbury HC, Newlands SD, eds. Head \& Neck Surgery-Otolaryngology Philadelphia: Lippincott Williams \& Wilkins, 2001:617-626.

9. Sataloff RT, Hawkshaw M, Ressue J. Granular cell tumor of the larynx. Ear Nose Throat J. 1998;77:582-4

10. Scala WA, Fernandes AM, Duprat Ade C, Costa HO. Granular cell tumor of the larynx in children: a case report. Braz J Otorhinolaryngol. 2008;74:780-5.

11. White JB, Glade R, Rossi CT, Bielamowicz S. Granular cell tumors of the larynx: diagnosis and management. J Voice. 2009;23:516-7.

\section{Corresponding author:}

Sedat Aydın M.D., Istasyon caddesi merdivenli sokak no 5 / 6 Kartal, Istanbul, Turkey 34860; e-mail: sedataydin63@yahoo.com 